\title{
Monodisperse Yolk-Shell Nanoparticles with a Hierarchical Porous Structure for Delivery Vehicles and Nanoreactors**
}

\author{
Jian Liu, Shi Zhang Qiao, * Sandy Budi Hartono, and Gao Qing (Max) Lu*
}

Core-shell and hollow structures are powerful platforms for controlled release, confined nanocatalysis, and optical and electronic applications. ${ }^{[1-3]}$ A hybrid of core-shell and hollow structures, a special class of core-shell structure with a distinctive core@void@shell configuration, which are called yolk-shell or rattle-type structures, have attracted tremendous interest in recent years. ${ }^{[1 \mathrm{a}, 4]}$ With the unique properties of movable cores, interstitial hollow spaces, and the functionality of shells, yolk-shell structures have great potential for application in various fields, such as nanoreactors, ${ }^{[4]}$ biomedicine,${ }^{[5]}$ lithium-ion batteries ${ }^{[6]}$ and photocatalysis. ${ }^{[7]}$

Currently, most research efforts in this area are directed to developing new synthetic approaches for yolk-shell materials with different components and shell structures. One general strategy is a template-assisted selective etching approach in which the core particle is coated with double shells consisting of different materials. The inner shell is then selectively removed by using a solvent or calcination. ${ }^{[4 a, 8,9]}$ Despite its conceptual simplicity, this approach is often associated with some disadvantages, such as low efficiency and tedious processing steps, which mainly arise from the difficulty in ensuring that the reaction takes place exclusively inside the shells. Yolk-shell materials with various components were also fabricated by Kirkendall ${ }^{[3 a, 5 a]}$ or Ostwald ripening ${ }^{[6 a, 7]}$ processes. However, these methods are limited to yolk-shell nanostructures in which the core and shell are made of the same material, and there is no effective control over the wall thickness and shell structure. ${ }^{[10,11]}$ Recently, a one-step encapsulation of particles by silica shells in an aqueous mixture of lauryl sulfonate betaine (LSB) and sodium dodecyl benzenesulfonate (SDS) was developed ${ }^{[10]}$ to produce yolk-

[*] Dr. J. Liu, Prof. Dr. S. Z. Qiao, S. Budi Hartono, Prof. Dr. G. Q. Lu ARC Centre of Excellence for Functional Nanomaterials Australian Institute for Bioengineering and Nanotechnology The University of Queensland

Queensland, QLD 4072 (Australia)

Fax: $(+61)$ 7-3365-6074

E-mail: s.qiao@uq.edu.au maxlu@uq.edu.au

[**] This work was financially supported by the Australian Research Council (ARC) through Linkage Project program (LP0882681), Discovery Project program (DP1094070, DP1095861), and the ARC Centre of Excellence for Functional Nanomaterials. J.L. gratefully acknowledges the award of U.Q. Postdoctoral Research Fellowship, and a UQ Early-Career-Research Grant. The authors are grateful to Dr. Zhen Li for providing gold nanoparticles, Dr. Zhi Gang Chen for help in taking TEM images, Dr. Hong Zhang for calculations, Frances Stahr and Dr. Qiu Hong Hu for providing mesoporous silica nanoparticles, and Prof. Chengzhong Yu for fruitful discussions. Supporting information for this article is available on the WWW under http://dx.doi.org/10.1002/anie.201001252. shell structures. This tedious method still required an additional co-structure-directing agent, such as 3-aminopropyltriethoxysilane (APTES), and it was difficult to control the structure parameters and wall thicknesses. Furthermore, the shell produced is nonporous. Thus, it remains an interesting challenge to fabricate size-tunable porous yolk-shell nanostructures composed from different cores and shells with various sizes, shapes, components, and functions by a simple solution approach. These multifunctional yolk-shell nanostructures are particularly relevant to the controlled loading and release of functional species ${ }^{[5 \mathrm{~d}, 9 \mathrm{c}, \mathrm{d}]}$ and are also ideal nanoreactors to realize confined and cooperative catalysis. ${ }^{[11,12]}$

Mesoporous yolk-shell nanostructures could exhibit unique release properties for drug/gene delivery because of their hierarchical porous structures ${ }^{[9]}$ and good catalystloading properties for confined cooperative catalysis, as they can prevent aggregation of catalysts and promote the mass diffusion and transport of reactants. ${ }^{[1 \mathrm{c}, 2 \mathrm{~d}, 3 \mathrm{~b}, 4,12]}$ Herein, we report a general method to produce yolk-shell structures with mesoporous shells and tunable wall thickness using a vesicle templating approach. Various yolk-shell structures with different types of cores (such as silica spheres, mesoporous silica spheres or rods, gold particles, AuNPs@SiO ${ }_{2}$ nanospheres, or magnetic $\mathrm{Fe}_{3} \mathrm{O}_{4}$ particles) and different particle sizes (200-700 nm) were successfully prepared. It is important to note that the yolk-shell silica materials prepared by this method have highly uniform particle sizes and porous silica shells, and the pore size and the shell thickness can be tuned to a certain extent. The hierarchical porous yolk-shell structures with ordered mesoporous silica cores and mesoporous silica shells were synthesized for the first time, and their use as delivery vehicles and nanoreactors was demonstrated.

The procedure for the preparation of yolk-shell structures with a mesoporous shell is shown in Scheme 1. The first step involves in the preparation of the core-vesicle complex from the fluorocarbon surfactant $\left[\mathrm{C}_{3} \mathrm{~F}_{7} \mathrm{O}\left(\mathrm{CF}\left(\mathrm{CF}_{3}\right) \mathrm{CF}_{2} \mathrm{O}\right)_{2} \mathrm{CF}\right.$ $\left.\left(\mathrm{CF}_{3}\right) \mathrm{CONH}\left(\mathrm{CH}_{2}\right)_{3} \mathrm{~N}^{+}\left(\mathrm{C}_{2} \mathrm{H}_{5}\right)_{2} \mathrm{CH}_{3}\right] \mathrm{I}^{-}$, which is denoted $\mathrm{FC} 4$, $(\mathrm{EO})_{106}(\mathrm{PO})_{70}(\mathrm{EO})_{106}(\mathrm{~F} 127)$, and core materials by electrostatic interactions and a synergetic effect. In the next step, a mesostructured silica shell is deposited on the surface of the core-vesicle complex by a vesicle-templating approach and the simultaneous sol-gel polymerization of tetraethoxysilane (TEOS). Finally, following shrinkage of silicate shell and ripening processes during the hydrolysis and condensation of TEOS, the yolk-shell structures are obtained. The mesoporous shells are formed after the calcination to remove the surfactants. 


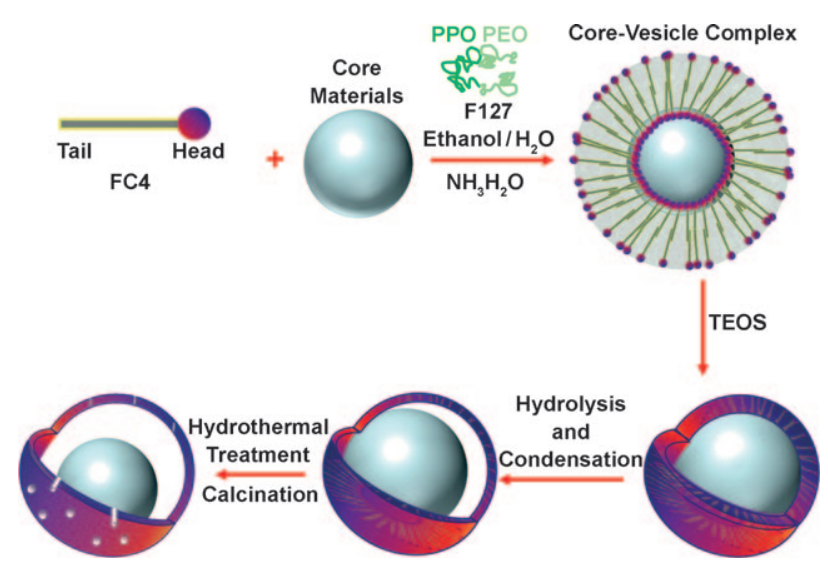

Scheme 1. Procedure for the preparation of yolk-shell structures with a mesoporous shell. FC4 = fluorocarbon surfactant (see text), PPO = poly (propylene oxide), PEO= poly (ethylene oxide), TEOS $=$ tetraethoxysilane.

Figure $1 \mathrm{a}, \mathrm{b}$ shows scanning electron microscopy (SEM) and transmission electron microscopy (TEM) images of the yolk-shell structured nanospheres synthesized using silica spheres (ca. $260 \mathrm{~nm}$ ) as the cores (denoted as SS260-YS). It is apparent that highly uniform and monodisperse silica yolkshell spheres with a size of $420 \mathrm{~nm}$ are obtained, and each silica particle is encapsulated by a thin shell with a thickness of $16 \mathrm{~nm}$. The product is obtained in quantatitive yield. The SEM image in Figure 1 a also shows some of the broken spheres and the exposed cores of the yolk-shell particles after
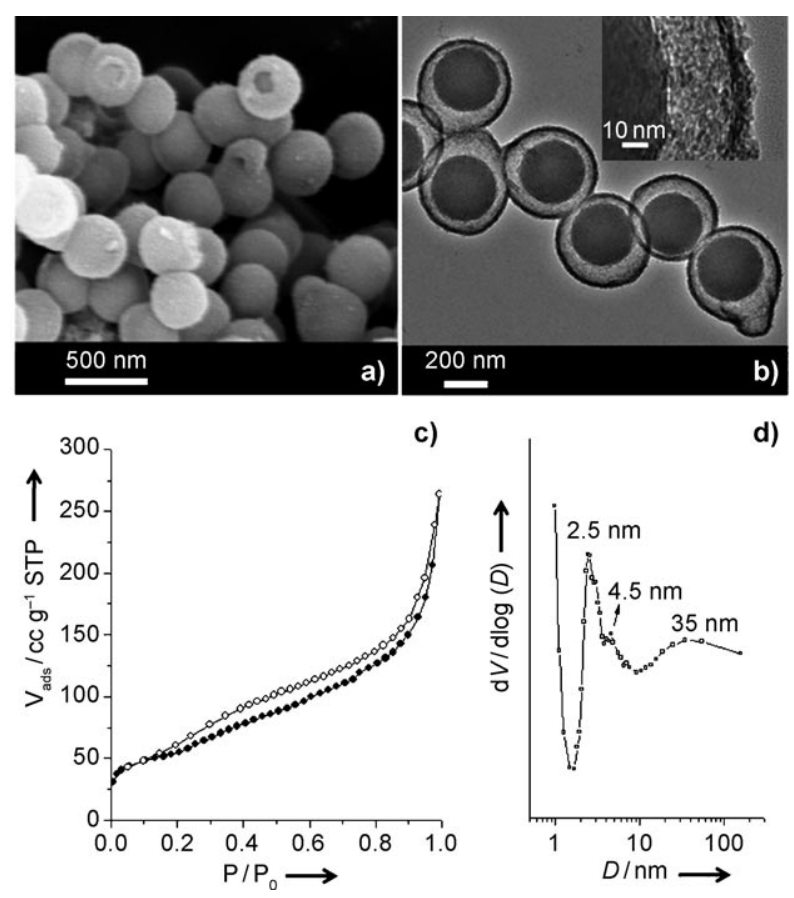

Figure 1. Yolk-shell material synthesized using silica spheres with $260 \mathrm{~nm}$ as core. a) SEM image, b) TEM image, c) nitrogen sorption isotherm; $V_{\text {ads }}=$ adsorbed volume (cubic centimeters per gram at standard temperature and pressure), and d) $\mathrm{BJH}$ pore size distribution. mechanical fracturing, providing evidence of a hollow structure. We believe the cores to be free to move, because only one silica sphere is encapsulated into a mesoporous silica shell. Wormhole-like mesopores with diameters of about 2$3 \mathrm{~nm}$ exist in the silica shell, as confirmed by the TEM and nitrogen sorption analyses (Figure $1 \mathrm{~b}-\mathrm{d}$ ). Figure $1 \mathrm{c}, \mathrm{d}$ shows the nitrogen sorption isotherm and the corresponding pore size distribution curve of SS260-YS. A type IV isotherm with a steep hysteresis loop at relative pressure $P / P_{0}$ of $0.2-0.4$ is observed, indicating that this sample has a mesoporous structure with uniform pore size. The Barrett-JoynerHalenda $(\mathrm{BJH})$ pore size distribution curve further confirms the uniform mesopore size centered around $2.5 \mathrm{~nm}$; the pore size distribution centered at $35 \mathrm{~nm}$ is attributed to the mesopores between interparticles. The sample has a Brumauer-Emmet-Teller (BET) surface area of $195 \mathrm{~m}^{2} \mathrm{~g}^{-1}$, with a total pore volume of $0.32 \mathrm{~cm}^{3} \mathrm{~g}^{-1}$.

To control the shell thickness of the yolk-shell nanoparticles (NPs), the amount of TEOS was adjusted from 5 to $20 \mathrm{mmol}$ whilst keeping the other synthesis parameters constant. The resultant silica materials have a yolk-shell structure with diameters of $400-540 \mathrm{~nm}$, but the shell thickness can be tailored from $10 \mathrm{~nm}$ to $50 \mathrm{~nm}$ (Supporting Information, Figure S1). However, some silica NPs are coexistent with yolk-shell particles at very high TEOS concentrations $(20 \mathrm{mmol})$. It is worth mentioning that yolkshell structures can be obtained in a large range of reactant molar ratios (Supporting Information, Figure S2-S5). Moreover, by tailoring the amount of F127 and the FC4/F127 molar ratio in the initial mixture, the shell thickness and pore size can be tuned (Supporting Information, Figure S2-S5, Table S1). The increase in the molar ratio of $\mathrm{FC} 4 / \mathrm{F} 127$ favors the formation of a core-shell structure over a yolkshell structure (Supporting Information, Figure S4).

Under the similar conditions to the preparation of sample SS260-YS, yolk-shell materials with various particle sizes can be synthesized using differently sized core silica spheres (120, 260, and $700 \mathrm{~nm})$. The TEM image reveals that 170 and $420 \mathrm{~nm}$ uniform yolk-shell nanospheres are obtained using silica spheres with sizes of 120 and $260 \mathrm{~nm}$ as cores, respectively (Supporting Information, Figure S6a,d,b,e). Upon increasing the core size further to $700 \mathrm{~nm}$, yolk-shell microspheres associated with a large amount of hollow nanocapsules were obtained (Supporting Information, Figure S6c,f). It is likely that the shell can accommodate the core particles with particle sizes smaller than $700 \mathrm{~nm}$.

To investigate the formation mechanism of such yolkshell structures, TEM was used to monitor the synthesis process of SS260-YS. (The dynamic transformation for SS260YS during the synthesis process is shown in the Supporting Information, Figure S7.) After TEOS was added into the synthesis system, a silica shell with a thickness of approximately $50 \mathrm{~nm}$ was formed on the silica spheres within the first $1 \mathrm{~h}$ because of the assembly of TEOS onto the vesicle template (Supporting Information, Figure S7a,b). Upon increasing the reaction time to $20 \mathrm{~h}$, the shell thickness became thinner (from $50 \mathrm{~nm}$ to $25 \mathrm{~nm}$ ), and the hollow space between core and shell became wider (from $8 \mathrm{~nm}$ to $50 \mathrm{~nm}$; Supporting Information, Figure S7f). After the hydrothermal 
process, the shell thickness was further decreased to $16 \mathrm{~nm}$, and the hollow space was further increased to $100 \mathrm{~nm}$ (Figure $1 \mathrm{~b}$ ). The formation of such a yolk-shell structure was probably a cooperative process of vesicle templating, ripening, and shrinkage of the silica shell. Herein, we propose that ethanol can decrease the electrostatic repulsion of the negatively charged groups of FC4, and vesicles around 200$400 \mathrm{~nm}$ can be formed in such synthesis conditions. ${ }^{[3 \mathrm{~d}]}$ Owing to the synergetic effect between FC4 and core materials, the soft vesicle produced by FC4 was assembled on the silica sphere core to form the core-vesicle complex. The silane (TEOS) then hydrolyzed and condensed on the vesicle template through electrostatic attractions and formed the core-shell structure with the vesicle-core complex. During this sol-gel process, small silica NPs were produced that stuck to the vesicle surface, and mesoporous shells were formed by the cooperative interaction between silica NPs and FC4. Finally, growth, self-assembly, ripening, and shrinkage of the silica shell, owing to the further condensation of silica, led to the formation of yolk-shell structures (Scheme 1). The use of FC4 is essential for forming the vesicle-core complex template. When large amounts of TEOS were used, the more silane hydrolyzed and condensed at the interface of vesicle-core template, and yolk-shell silica with a thicker shell can be obtained. A vesicle-core complex cannot be formed with a very large size core, and $700 \mathrm{~nm}$ silica spheres cannot be optimally encapsulated in current synthesis conditions. These interesting observations in our research might be explained by the vesicle-core templating formation mechanisms discussed above.

Along with the ability to encapsulate spherical particles into the $\mathrm{SiO}_{2}$ shell, this general synthetic method can be extended to prepare yolk-shell structures with different components and shapes simply by replacing core materials. Figure $2 \mathrm{a}-\mathrm{d}$ shows the resulting yolk-shell structure with different mesoporous silica materials as core particles. Mesoporous silica NPs with a spherical morphology, such as IBN1 (particle size $100 \mathrm{~nm}$, pore size $5.8 \mathrm{~nm}$ ) ${ }^{[13]}$ and MCM41 (particle size $200 \mathrm{~nm}$, pore size $2.1 \mathrm{~nm})^{[14]}$ can be encapsulated into the silica shell to form uniform hierarchical porous yolkshell structures (Figure 2a,b). Interestingly, this method can also encapsulate particles with different shapes. When mesoporous SBA15 long nanorods $(1300 \mathrm{~nm}$ long, $140 \mathrm{~nm}$ diameter, pore size $5.7 \mathrm{~nm})^{[15]}$ or mesoporous short IBN4 nanorods $(200 \mathrm{~nm} \text { long, } 50 \mathrm{~nm} \text { diameter, pore size } 6.2 \mathrm{~nm})^{[13]}$ were used as the core materials, the resulting products kept the nanorod morphology with a rather uniform thickness mesoporous silica shell (Figure $2 \mathrm{c}, \mathrm{d}$ ). The resulting materials are denoted as IBN1-YS, MCM41-YS, SBA15NR-YS, and IBN4-YS, respectively. Further studies showed that this method can be extended to encapsulate other particles of different composition, such as $\mathrm{Fe}_{3} \mathrm{O}_{4}$ (Figure 2e) and AuNPs (Figure $2 \mathrm{f}$ ). The UV/Vis extinction of $\mathrm{Au} @ \mathrm{SiO}_{2}$ yolk-shell particles appears at $542 \mathrm{~nm}$ in ethanol (Supporting Information, Figure S8), which is red-shifted by $12 \mathrm{~nm}$ relative to that of bare gold particles, thus reflecting the high refractive index of silica (1.458) and the permeability of the silica shells. $\mathrm{N}_{2}$ adsorption-desorption isotherms and pore size distributions of these samples are presented in Figure $2 \mathrm{~g}, \mathrm{~h}$ and the
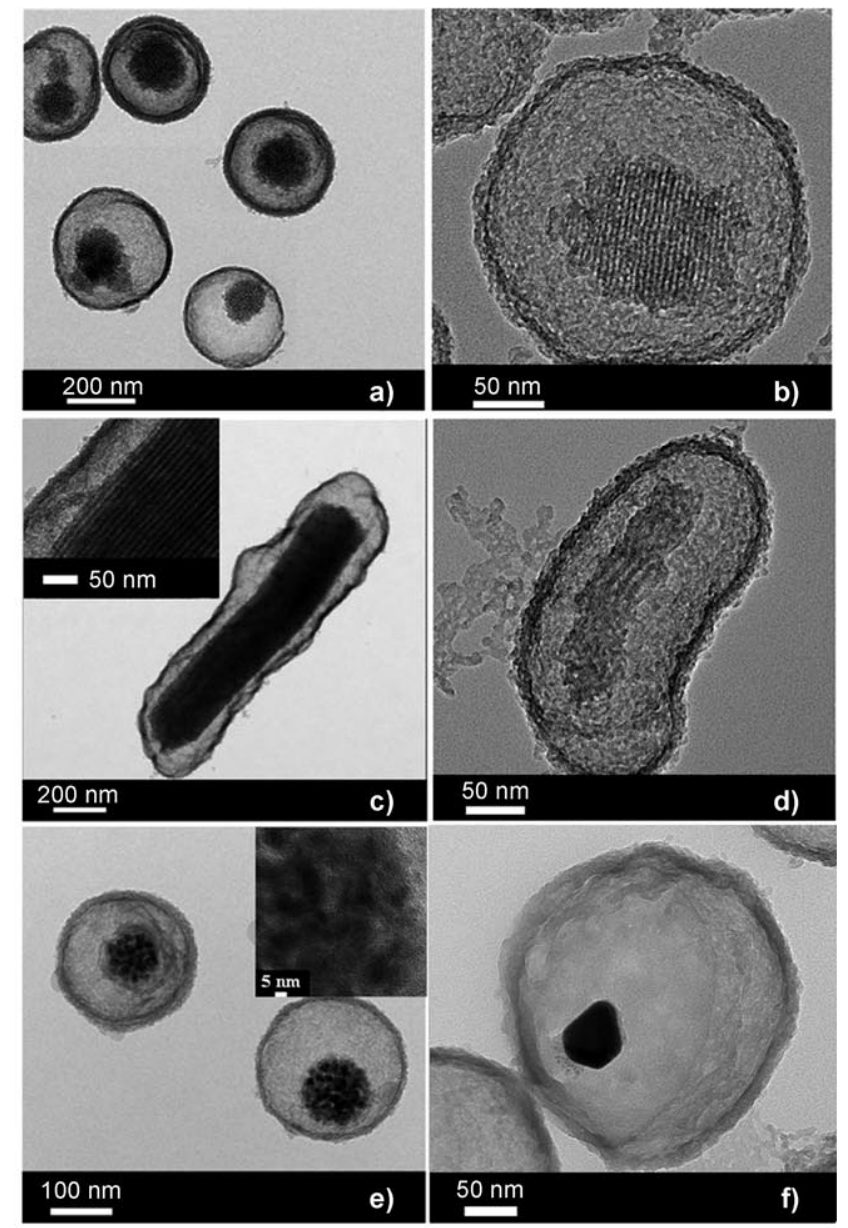

g)

h)
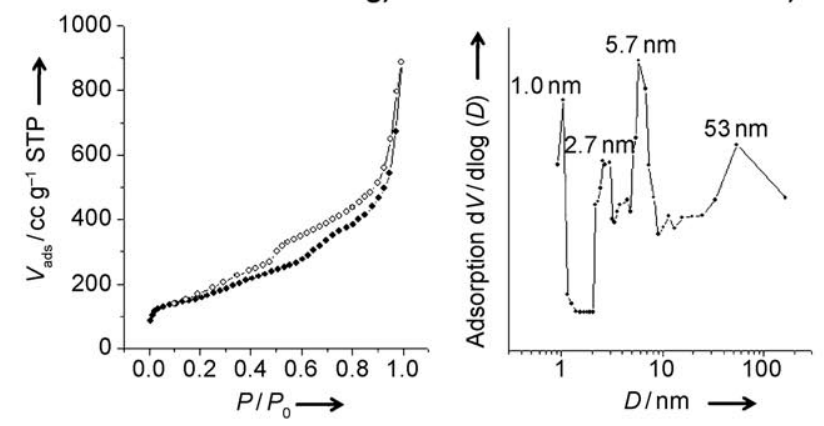

Figure 2. TEM images of various yolk-shell materials: a) IBNI-YS, b) MCM41LP-YS, c) SBA15NR-YS, d) IBN4-YS, e) $\mathrm{Fe}_{3} \mathrm{O}_{4}-\mathrm{YS}$, and f) AuYS. g) Nitrogen sorption isotherm and h) $\mathrm{BJH}$ pore size distribution of SBA15NR-YS

Supporting Information, Figure S9. SBA15NR-YS shows a type IV isotherm with three capillary condensation steps at relative pressures $P / P_{0}$ of $0.25-0.45,0.5-0.7$, and $0.8-0.9$, respectively (Figure $2 \mathrm{~g}, \mathrm{~h}$ ), which is a characteristic of hierarchical porous architectures. The pore size distribution curve shows that the primary, secondary, tertiary, and quaternary pore diameters are centered at $1.0 \mathrm{~nm}, 2.7 \mathrm{~nm}, 5.7 \mathrm{~nm}$, and $53 \mathrm{~nm}$, respectively (Figure $2 \mathrm{~h}$ ), indicating that the materials have unique hierarchical porous structures on at least four levels: a) micropores in SBA15NR (ca. $1.0 \mathrm{~nm}$ ), b) uniform 
wormlike mesopores in the silica shell $(2.7 \mathrm{~nm})$, c) highly ordered mesopores in the silica core $(5.7 \mathrm{~nm})$, and d) mesopores between the interparticles $(53 \mathrm{~nm})$. Furthermore, the resulting yolk-shell material has a large surface area $\left(325 \mathrm{~m}^{2} \mathrm{~g}^{-1}\right)$ and a high total pore volume $\left(0.68 \mathrm{~cm}^{3} \mathrm{~g}^{-1}\right)$.

The embedded materials (such as silica and mesoporous silica spheres) can be either sealed inside for protection or made accessible to the outside environment by engineering the shell to be porous, thus enabling applications in many biomedical fields. ${ }^{[3,9]}$ We demonstrate the unique drug delivery profile associated with the hierarchical porous yolk-shell structure using ibuprofen as a model drug molecule. There is an apparent three-stage release pattern of ibuprofen from the rattle structures of IBN1-YS (Supporting Information, Figure S10). The first stage involves the rapid elution of ibuprofen within the first $60 \mathrm{~min}$, followed by a plateau $(54 \%)$ with only small changes during $1-5 \mathrm{~h}$. We believe that the ibuprofen molecules delivered during this stage are mainly for those adsorbed on the external surface. In the second stage, the release amount of ibuprofen increases again from 5 to $8 \mathrm{~h}$ and reaches another plateau at $63 \%$. It is reasonable to attribute this release to those trapped in the porous silica shell and the inner hollow spaces. In the third stage, the ibuprofen concentration increases again from 24 to $72 \mathrm{~h}$, and eventually reaches another plateau at $75 \%$. The release in the last stage is probably attributed to the adsorbed drug in the mesoporous silica IBN1 cores. The three-step release profile is associated with this particular mesoporous and yolk-shell structure. It is potentially possible to include two or more different drugs in the core and shell regions so that their delivery can be achieved in a programmed sequence through the structure design of yolk-shell materials.

The interior void can also be used as a reaction chamber or a nanoreactor in which chemical reaction processes may present vast differences because of the confining effect and change in microenvironments. To develop the nanoreactor, yolk-shell nanostructures containing AuNPs doped onto silica spheres as cores were designed using this method. First, AuNPs around $2 \mathrm{~nm}$ were coated onto the silica spheres (Supporting Information, Figure S11a-c). Gold-functionalized silica particles (AuNPs@SiO 2 ) were then encapsulated into the vesicle to form the yolk-shell with size around $440 \mathrm{~nm}$ containing AuNPs doped onto silica spheres (Supporting Information, Figure S11d). We expect that these types of yolk-shell materials may have great potential applications in nanoreactors.

In summary, we have developed a general and facile template strategy for the fabrication of a new class of nanostructured materials, so-called yolk-shell structured materials with movable cores and porous shells. Our approach is demonstrated by encapsulating silica spheres, mesoporous silica NPs, gold particles, magnetic particles, and $\mathrm{Au} @ \mathrm{SiO}_{2}$ NPs in a porous silica shell. Noteworthy is that the hierarchical mesoporous yolk-shell structures were obtained for the first time by encapsulating mesoporous silica NPs into the mesoporous silica shell through this method. A three-step release profile of drugs was observed with these particular mesoporous rattle-type structures. AuNPs@silica was used as a multicore to produce the yolk-shell structured nanoreactor.
This aspect of the work is expected to motivate further in situ studies of the formation mechanisms and the fabrication and applications of various nanoreactors. The yolk-shell materials, such as those developed in this work, could lead to new avenues for developing nanoreactors, drug/gene delivery vehicles, as well as photonic crystals.

\section{Experimental Section}

Details on the synthesis of the core materials are described in the Supporting Information. In a typical synthesis of yolk-shell structured materials with mesoporous silica shells, FC4 $(0.16 \mathrm{~g})$ and F127 (0$0.26 \mathrm{~g})$ were dissolved in a mixture of water $(18 \mathrm{~mL})$ and ethanol $(8 \mathrm{~mL})$. Then aqueous ammonia $(0.2 \mathrm{~mL}, 28 \mathrm{wt} \%)$ and an aqueous solution of core material $\left(2 \mathrm{~mL}, 30 \mathrm{mg} \mathrm{mL}^{-1}\right)$ were added and stirred at $30^{\circ} \mathrm{C}$ for more than $3 \mathrm{~h}$. TEOS $(0.44 \mathrm{~g})$ was then added to the mixture and stirred at $30^{\circ} \mathrm{C}$ for $20 \mathrm{~h}$, and subsequently heated at $100^{\circ} \mathrm{C}$ for $24 \mathrm{~h}$ in a Teflon-lined autoclave. The solid product was recovered by filtration and air-dried at $50^{\circ} \mathrm{C}$ overnight. The dry composite silica powder was further calcined at $550^{\circ} \mathrm{C}$ for $6 \mathrm{~h}$ in air to remove the organic templates. The resulting yolk-shell materials were denoted as X-YS, where $\mathrm{X}$ is the core material $(\mathrm{SS}=120 \mathrm{~nm}, 260 \mathrm{~nm}$, and $700 \mathrm{~nm}$ silica spheres; IBN1, MCM41, IBN4, SBA15NR, Au, $\mathrm{Fe}_{3} \mathrm{O}_{4}$ ) and $\mathrm{YS}=$ yolk-shell. (The details of the synthetic parameters of different yolk-shell structured materials are given in the Supporting Information, Table S1.)

Received: March 2, 2010

Published online: May 28, 2010

Keywords: controlled release $\cdot$ nanoparticles $\cdot$ nanoreactors vesicles

[1] a) X. W. Lou, L. A. Archer, Z. Yang, Adv. Mater. 2008, 20, 3987; b) J. H. Gao, H. W. Gu, B. Xu, Acc. Chem. Res. 2009, 42, 22; c) D. M. Vriezema, M. C. Aragonès, J. A. A. W. Elemans, J. J. L. M. Cornelissen, A. E. Rowan, R. J. M. Nolte, Chem. Rev. 2005, 105, 1445; d) S. F. M. van Dongen, H.-P. M. de Hoog, R. J. R. W. Peters, M. Nallani, R. J. M. Nolte, J. C. M. van Hest, Chem. Rev. 2009, 109, 6212; e) Y. Zhao, L. Jiang, Adv. Mater. 2009, 21, 3621; f) Q. Zhang, W. S. Wang, J. Goebl, Y. D. Yin, Nano Today 2009, 4, 494; g) X. J. Wu, D. S. Xu, Adv. Mater. 2010, 22, 1516.

[2] a) S. H. Joo, J. Y. Park, C. K. Tsung, Y. Yamada, P. D. Yang, G. A. Somorjai, Nat. Mater. 2009, 8, 126; b) J. Kim, J. E. Lee, J. Lee, J. H. Yu, B. C. Kim, K. An, Y. Hwang, C. H. Shin, J. G. Park, J. Kim, T. Hyeon, J. Am. Chem. Soc. 2006, 128, 688; c) J. P. Ge, Q. Zhang, T. R. Zhang, Y. D. Yin, Angew. Chem. 2008, 120, 9056; Angew. Chem. Int. Ed. 2008, 47, 8924; d) P. M. Arnal, M. Comotti, F. Schüth, Angew. Chem. 2006, 118, 8404; Angew. Chem. Int. Ed. 2006, 45, 8224; e) L. Zhang, S. Z. Qiao, Y. G. Jin, Z. G. Chen, H. C. Gu, G. Q. Lu, Adv. Mater. 2008, 20, 805; f) L. Zhang, S. Z. Qiao, Y. G. Jin, H. G. Yang, S. Budihartono, F. Stahr, Z. F. Yan, X. L. Wang, Z. P. Hao, G. Q. Lu, Adv. Funct. Mater. 2008, 18, 3203; g) Y. Deng, D. Qi, C. Deng, X. Zhang, D. Y. Zhao, J. Am. Chem. Soc. 2008, 130, 28; h) J. P. Yang, Y. H. Deng, Q. L. Wu, J. Zhou, H. F. Bao, Q. Li, F. Zhang, F. Y. Li, B. Tu, D. Y. Zhao, Langmuir 2010, DOI: 10.1021/la904596x.

[3] a) Y. D. Yin, R. M. Rioux, C. K. Erdonmez, S. Hughes, G. A. Somorijai, A. P. Alivisatos, Science 2004, 304, 711; b) J. Liu, Q. H. Yang, L. Zhang, H. Q. Yang, J. S. Gao, C. Li, Chem. Mater. 2008, 20, 4268; c) H. Djojoputro, X. F. Zhou, S. Z. Qiao, L. Z. Wang, C. Z. Yu, G. Q. Lu, J. Am. Chem. Soc. 2006, 128, 6320; 
d) J. Liu, S. B. Hartono, Y. G. Jin, Z. Li, G. Q. Lu, S. Z. Qiao, J. Mater. Chem. 2010, DOI: 10.1039/b925201k.

[4] a) K. Kamata, Y. Lu, Y. N. Xia, J. Am. Chem. Soc. 2003, 125, 2384; b) J. Lee, J. C. Park, H. Song, Adv. Mater. 2008, 20, 1523; c) D. Van Gough, A. Wolosiuk, P. V. Braun, Nano Lett. 2009, 9, 1994.

[5] a) J. H. Gao, G. Liang, B. Zhang, Y. Kuang, X. Zhang, B. Xu, J. Am. Chem. Soc. 2007, 129, 1428; b) Y. S. Lin, S. H. Wu, C. T. Tseng, Y. Hung, C. Chang, C. Y. Mou, Chem. Commun. 2009, 3542; c) W. R. Zhao, H. R. Chen, Y. S. Li, L. Li, M. D. Lang, J. L. Shi, Adv. Funct. Mater. 2008, 18, 2780; d) Y. F. Zhu, T. Ikoma, N. Hanagata, S. Kaskel, Small 2010, 6, 471.

[6] a) J. Liu, H. Xia, D. F. Xue, L. Lu, J. Am. Chem. Soc. 2009, 131, 12086; b) X. W. Lou, C. M. Li, L. A. Archer, Adv. Mater. 2009, 21,2536 ; c) K. T. Lee, Y. S. Jung, S. M. Oh, J. Am. Chem. Soc. 2003, 125, 5652; d) W. M. Zhang, J. S. Hu, Y. G. Guo, S. F. Zheng, L. S. Zhong, W. G. Song, L. J. Wan, Adv. Mater. 2008, 20, 1160

[7] H. X. Li, Z. F. Bian, J. Zhu, Y. N. Huo, H. X. Li, Y. F. Lu, J. Am. Chem. Soc. 2007, 129, 8406
[8] D. K. Yi, S. S. Lee, G. C. Papaefthymiou, J. Y. Ying, Chem. Mater. 2006, 18, 614.

[9] a) T. R. Zhang, J. P. Ge, Y. X. Hu, Q. Zhang, S. Aloni, Y. D. Yin, Angew. Chem. 2008, 120, 5890; Angew. Chem. Int. Ed. 2008, 47, 5806; b) D. Chen, L. L. Li, F. Q. Tang, S. Qi, Adv. Mater. 2009, 21, 3804; c) Q. Zhang, J. P. Ge, J. Goebl, Y. X. Hu, Z. D. Lu, Y. D. Yin, Nano Res. 2009, 2, 583; d) Y. Chen, H. R. Chen, L. M. Guo, Q. J. He, F. Chen, J. Zhou, J. W. Feng, J. L. Shi, ACS Nano 2010, $4,529$.

[10] X. J. Wu, D. S. Xu, J. Am. Chem. Soc. 2009, 131, 2774.

[11] G. L. Li, Q. Shi, S. J. Yuan, K. G. Neoh, E. T. Kang, X. L. Yang, Chem. Mater. 2010, 22, 1309.

[12] H. Q. Yang, L. Zhang, L. Zhong, Q. H. Yang, C. Li, Angew. Chem. 2007, 119, 6985; Angew. Chem. Int. Ed. 2007, 46, 6861.

[13] Y. Han, J. Y. Ying, Angew. Chem. 2005, 117, 292; Angew. Chem. Int. Ed. 2005, 44, 288.

[14] Q. Cai, Z. S. Luo, W. Q. Pang, Y. W. Fan, X. H. Chen, F. Z. Cui, Chem. Mater. 2001, 13, 258.

[15] X. L. Ji, K. T. Lee, M. Monjauze, L. F. Nazar, Chem. Commun. 2008, 4288 


\section{Angewandte}

Supporting Information

(C) Wiley-VCH 2010

69451 Weinheim, Germany

Monodisperse Yolk-Shell Nanoparticles with a Hierarchical Porous Structure for Delivery Vehicles and Nanoreactors**

Jian Liu, Shi Zhang Qiao, * Sandy Budi Hartono, and Gao Qing (Max) Lu*

anie_201001252_sm_miscellaneous_information.pdf 


\section{Contents of Supporting Information}

\section{S1. Experimental Section}

2. Table S1. Physicochemical Properties of Different Yolk-shell Structured Materials

3. Figure S1 Representative TEM images of the yolk-shell (SS260-YS, synthesized by using silica spheres with $260 \mathrm{~nm}$ as core) with different thickness synthesized at different TEOS molar amount a) TEOS $=5 \mathrm{mmol}$, b) TEOS $=15 \mathrm{mmol}$, and c) TEOS=20 mmol.

4. Figure S2. a), b), c) SEM images and d), e), f) TEM images of the yolk-shell nano-spheres synthesized using silica spheres with $260 \mathrm{~nm}$ as core and different amount of F127. a) and d) $0 \mathrm{~g}$; b) and e) $0.13 \mathrm{~g}$; c) and f) $0.26 \mathrm{~g}$.

5. Figure S3. Nitrogen-sorption isotherms of the yolk-shell nano-spheres synthesized using silica spheres with $260 \mathrm{~nm}$ as cores and different amount of F127. a) $0 \mathrm{~g}$; b) $0.13 \mathrm{~g}$; c) $0.26 \mathrm{~g}$.

6. Figure S4. Effect of FC4 amount on the morphological transformation of products with changing the FC4/F127 ratio: a), b), c) SEM images and d), e), f) TEM images. a) and d) FC4/F127=24; b) and e) FC4/F127=48; c) and f) FC4/F127=72.

7. Figure S5. Nitrogen-sorption isotherm of yolk-shell nano-structured products with changing the FC4/F127 ratio: a), FC4/F127=24; b), FC4/F127=48; c), FC4/F127=72.

8. Figure S6. Effect of core size on the morphological transformation of products: a), b), c) SEM images and d), e), f) TEM images. a) and d) core size $=120 \mathrm{~nm}$; b) and e) core size $=260 \mathrm{~nm} ; \mathrm{c}$ ) and f) core size $=700 \mathrm{~nm}$.

9. Figure S7. TEM images showing the structural evolution of SS260-YS as a function of time (starting from addition of TEOS into the solution). Panels a), b), c), d), e) and f) correspond to reaction times of $30 \mathrm{~min}, 1 \mathrm{~h}, 2 \mathrm{~h}, 4 \mathrm{~h}, 6 \mathrm{~h}$, and f) $20 \mathrm{~h}$, respectively.

10.Figure S8. UV-vis spectra of a) Au particles; and b) $\mathrm{Au} @ \mathrm{SiO}_{2}$ yolk-shell particles in ethanol solution.

11. Figure S9. (A) Nitrogen-sorption isotherms and (B) BJH pore-size distributions of various yolk-shell materials: a) IBN1-YS, b) MCM41LP-YS, c) SBA15NR-YS, and d) IBN4-YS.

\section{S2. Calculation Models and Discussions}

13. Figure S10. The cumulative release curves of ibuprofen from IBN1-YS. Red solid line represents the results from experimental measurements, and blue dashed line represents the results from modelling calculations.

14. Figure S11. TEM images of a) $\mathrm{SiO}_{2}-\mathrm{Au}$, in which 2-nm Au nano-particles are assembled on $260 \mathrm{~nm}$ silica spheres; b) $\mathrm{SiO}_{2}$-Au-YS yolk-shell structures, in which 2-nm Au nano-particles coated on $260 \mathrm{~nm}$ silica spheres are encapsulated into the hollow silica shells.

\section{Reference}




\section{S1. Experimental Section}

\section{S1.1 Chemicals and Reagents}

All materials were analytical grade and used as received without any further purification. Triblock copolymer $\mathrm{EO}_{106} \mathrm{PO}_{70} \mathrm{EO}_{106}(\mathrm{~F} 127), \mathrm{EO}_{20} \mathrm{PO}_{70} \mathrm{EO}_{20}(\mathrm{P} 123)$, cetyltrimethylammonium bromide $(\mathrm{CTAB})$, tetraethyl orthosilicate $\mathrm{Si}\left(\mathrm{OC}_{2} \mathrm{H}_{5}\right)_{4}$ (TEOS) $(>99 \%)$, gold chloride $\left(\mathrm{HAuCl}_{4}\right.$ $3 \mathrm{H}_{2} \mathrm{O}$ ) were purchased from Aldrich. Fluorocarbon surfactant, FC4, was bought from Yick Vic Chemicals (Hong Kong). Water was purified by a Milli $Q$ system and had an electrical resistance of $18 \mathrm{M} \Omega \cdot \mathrm{cm}$.

\section{S1.2 Synthesis of Core Materials}

Synthesis of Monodisperse Silica Spheres: Monodisperse silica spheres were synthesized by modifiing a procedure reported in literature [1]. Different amount of ammonia aqueous solutions was mixed with a solution containing $250 \mathrm{~mL}$ of absolute ethanol (EtOH) and $20 \mathrm{~mL}$ of deionized water $\left(\mathrm{H}_{2} \mathrm{O}\right)$ to obtain silica spheres with different particle sizes. After stirring for $1 \mathrm{~h}$, $15 \mathrm{~mL}$ of TEOS was added to each of the solution and stirred for $6 \mathrm{~h}$ at room temperature. 5 $\mathrm{mL}, 10 \mathrm{~mL} \& 20 \mathrm{~mL}$ of $28 \mathrm{wt} \% \mathrm{NH}_{4} \mathrm{OH}$ led to silica nanospheres with 120,260 and $700 \mathrm{~nm}$ of particle size, respectively

Synthesis of $\mathrm{SiO}_{2}$-Au: After $25 \mathrm{mg}$ of thiol-terminated poly(methacrylic acid) (PMAA-DDT, $M_{n}=1800$, polymer dispersity $M_{w} / M_{n}=1.21$ ) was dissolved in $20 \mathrm{~mL}$ of Milli-Q water, $100 \mathrm{mg}$ of as-synthesized $\mathrm{SiO}_{2}$ nano-spheres $(D=260 \mathrm{~nm})$ were added into polymer solution under a magnetic stirring. The resultant suspension solution was mixed with $\mathrm{HAuCl}_{4}$ aqueous solution $(0.5 \mathrm{~mL}, \mathrm{C}=20 \mathrm{mM})$ and stirred for $30 \mathrm{~min}$. Then $0.5 \mathrm{~mL}$ of fresh $\mathrm{NaBH}_{4}$ solution $(2 \mathrm{mM})$ was quickly injected into the mixture and the mixture turned into brown within seconds. The solution was stirred for $30 \mathrm{~min}$ and then another $0.5 \mathrm{~mL}$ of $\mathrm{NaBH}_{4}$ solution was added. After stirring overnight, the $\mathrm{SiO}_{2}-\mathrm{Au}$ nano-composites were separated by centrifugation and washed three times with Milli-Q water. The obtained $\mathrm{SiO}_{2}-\mathrm{Au}$ nano-particles were dispersed in water and then used in the preparation of yolk-shell nano-structures.

Synthesis of MCM41 Mesoporous Silica Nano-spheres [2]: In a typical synthesis, $0.2 \mathrm{~g}$ of cetyltrimethylammonium bromide (CTAB) was mixed with $96 \mathrm{~mL}$ of water and $0.7 \mathrm{~mL}$ of $2 \mathrm{M}$ sodium hydroxide. This mixture was then stirred and heated to $80{ }^{\circ} \mathrm{C}$ in a water bath. Once at $80^{\circ} \mathrm{C}$, the solution was left for 20 minutes to ensure a uniform temperature, then $0.006 \mathrm{~mol}$ $(1.25 \mathrm{~g})$ of tetraethylorthosilicate (TEOS) was added. The solution was kept stirring vigorously for 2 hours. The white precipitates were collected via centrifugation and washed twice in $100 \mathrm{~mL}$ of ethanol and $2 \mathrm{~mL}$ of $32 \%$ concentrated hydrochloric acid at $60^{\circ} \mathrm{C}$ for 8 hours. The washed silica was dried in an oven at $50^{\circ} \mathrm{C}$.

Synthesis of IBN1 Mesoporous Silica Nano-spheres [3]: $0.65 \mathrm{~g}$ of Pluronic F127 and $0.8 \mathrm{~g}$ of FC4 were dissolved in $40 \mathrm{~mL}$ of $0.02 \mathrm{M} \mathrm{HCl}$ aqueous solution, then $2.2 \mathrm{~g}$ of TEOS was added. The solution was stirred at $30{ }^{\circ} \mathrm{C}$ for $20 \mathrm{~h}$ before it was transferred to an autoclave for further condensation at $100{ }^{\circ} \mathrm{C}$ for 1 day. The product was collected by centrifugation, dried in air, and calcined at $550{ }^{\circ} \mathrm{C}$ for $5 \mathrm{~h}$ to remove the surfactant.

Synthesis of IBN4 Mesoporous Silica Nano-particles [3]: $0.25 \mathrm{~g}$ of Pluronic P123 and 0.7 $\mathrm{g}$ of FC4 were dissolved in $40 \mathrm{~mL}$ of $0.02 \mathrm{M} \mathrm{HCl}$ solution, followed by the introduction of $1.0 \mathrm{~g}$ of TEOS. The solution was stirred at $30^{\circ} \mathrm{C}$ for $20 \mathrm{~h}$, then transferred into an autoclave and kept at $100^{\circ} \mathrm{C}$ for 1 day.

Synthesis of SBA-15 nano-rods (SBA15-NR) [4]: In a typical synthesis, $2 \mathrm{~g}$ of Pluronic $\mathrm{P} 123$ were dissolved in $360 \mathrm{~mL}$ of $2 \mathrm{M} \mathrm{HCl}$ at $38^{\circ} \mathrm{C} .4 .2 \mathrm{~g}$ of TEOS was added into the above solution with vigorous stirring. The concentrations of P123 and TEOS in the solution were 0.53 $w t \%$ and $1.1 \mathrm{wt} \%$, respectively. The mixture was stirred for $6 \mathrm{~min}$ and remained quiescent for 24 
$\mathrm{h}$ at $38{ }^{\circ} \mathrm{C}$. It was subsequently heated at $100{ }^{\circ} \mathrm{C}$ for another $24 \mathrm{~h}$ in an autoclave. The assynthesized SBA-15 was collected by centrifugation, dried and calcined at $550{ }^{\circ} \mathrm{C}$ in air.

Synthesis of Magnetic $\mathrm{Fe}_{3} \mathrm{O}_{4}$ /silica Composite Nanospheres: The $\mathrm{Fe}_{3} \mathrm{O}_{4} /$ silica composite nanospheres with size around $178 \mathrm{~nm}$ were prepared according to the previously reported method [5]. Briefly, (1) The sphere-like magnetite nanoparticle aggregates with a typical hydrodynamic size were prepared firstly and used as core of $\mathrm{Fe}_{3} \mathrm{O}_{4} /$ silica composite nanospheres; (2) The core-shell $\mathrm{Fe}_{3} \mathrm{O}_{4} /$ silica composite nanospheres were then synthesized via modified Stöber methods.

Synthesis of Au Nano-particles: Au nano-particles sol with a size of approximately $30 \mathrm{~nm}$ was synthesized according to the standard sodium citrate reduction method [6]. Briefly, $10 \mathrm{~mL}$ of $2 \mathrm{mM}$ gold(III) chloride trihydrate solution was refluxed and vigorously stirred for $10 \mathrm{~min}$. Once a rolling boil was achieved, $10 \mathrm{~mL}$ of $8 \mathrm{mM}$ trisodium citrate solution was added, and the mixture solution were then refluxed for $30 \mathrm{~min}$ to cause a slow color change from gray to pale red. After further boiling for $30 \mathrm{~min}$, the solution was allowed to cool to room temperature under stirring.

\section{S1.3 Characterization}

The shape, structure, and composition of the resulting samples were investigated using SEM, TEM and nitrogen sorption. SEM images of the samples coated with platinum were recorded on a JEOL 6300 microscope. TEM images were obtained by FEI Tecnai F20 and JEOL 2100 electron microscope. The powder samples for the TEM measurements were suspended in ethanol and then dropped onto the $\mathrm{Cu}$ grids with holey carbon films. Nitrogen sorption isotherms of samples were obtained by Quantachrome Autosorb-1 and Quadrasorb SI analyzer at $77 \mathrm{~K}$. Prior to the measurement, the samples were degassed at $120^{\circ} \mathrm{C}$ for at least $8 \mathrm{~h}$. The BrunauerEmmett-Teller (BET) specific surface areas were calculated using adsorption data at a relative pressure range of $P / P_{0}=0.05 \sim 0.25$. Pore size distributions were derived from the adsorption branch using Barrett-Joyner-Halenda (BJH) method. The total pore volumes were estimated from the amounts adsorbed at a relative pressure $\left(P / P_{0}\right)$ of 0.99 . An UV-Vis absorbance spectrophotometer (Shimadzu 2450) was used to determine the concentration of ibuprofen in supernatant solution at $264 \mathrm{~nm}$.

\section{S1.4 Ibuprofen Adsorption and Release}

Typically, a $10 \mathrm{mg} / \mathrm{mL}$ of ibuprofen-hexane solution was prepared at room temperature. Then, $100 \mathrm{mg}$ of the yolk-shell materials which was previously degassed at $100^{\circ} \mathrm{C}$ for overnight was added into $10 \mathrm{~mL}$ of the IBU-hexane solution. The mixture was sonicated for 30 minutes and then stirred for three days (72 hours). The solid materials were separated from the solution and dried at $50^{\circ} \mathrm{C}$. The amount of IBU adsorbed was determined from the difference in the solution concentrations (before and after adsorption). The solution concentration was determined using UV-VIS spectrophotometer (Shimadzu 2450) at a wavelength of $264 \mathrm{~nm}$. For release study, typically, $100 \mathrm{mg}$ of the sample that was saturated with ibuprofen was added into $40 \mathrm{~mL}$ PBS buffer solution ( $\mathrm{pH} \mathrm{7.4)} \mathrm{and} \mathrm{soaked} \mathrm{in} \mathrm{a} \mathrm{water} \mathrm{shaker.} \mathrm{The} \mathrm{release} \mathrm{profile} \mathrm{was} \mathrm{obtained} \mathrm{by}$ collecting $1 \mathrm{~mL}$ of sample from the mixture at a certain time. The sample was analyzed for the IBU concentration by using UV-VIS spectrophotometer at a wavelength of $264 \mathrm{~nm}$. 
Table S1. Physicochemical Properties of Different Yolk-shell Structured Materials

\begin{tabular}{|c|c|c|c|c|c|c|}
\hline Sample & $\begin{array}{l}\text { FC4 } \\
\text { amount } \\
\text { (g) }\end{array}$ & $\begin{array}{l}\text { F127 } \\
\text { amount } \\
\text { (g) }\end{array}$ & Core materials & $\begin{array}{l}\text { BET surface } \\
\text { area } \\
{\left[\mathrm{m}^{2} \mathrm{~g}^{-1}\right]}\end{array}$ & $\begin{array}{l}\text { Pore diameter } \\
\text { in shell } \\
\text { [nm] }\end{array}$ & $\begin{array}{l}\text { Total pore } \\
\text { volume } \\
{\left[\mathrm{cm}^{3} \mathrm{~g}^{-1}\right]}\end{array}$ \\
\hline$\overline{S S 260-Y S-1}$ & 0.16 & 0 & Silica Sphere $(260 \mathrm{~nm})$ & 195 & 2.5 & 0.32 \\
\hline SS260-YS-2 & 0.16 & 0.13 & Silica Sphere $(260 \mathrm{~nm})$ & 171 & 2.7 & 0.40 \\
\hline SS260-YS-3 & 0.16 & 0.26 & Silica Sphere $(260 \mathrm{~nm})$ & - & - & - \\
\hline SS260-YS-4 & 0.32 & 0.13 & Silica Sphere $(260 \mathrm{~nm})$ & 271 & - & 0.49 \\
\hline SS260-YS-5 & 0.64 & 0.13 & Silica Sphere $(260 \mathrm{~nm})$ & 251 & - & 0.38 \\
\hline SS120-YS & 0.16 & 0.13 & Silica Sphere $(120 \mathrm{~nm})$ & 207 & 3.0 & 0.52 \\
\hline SS700-YS & 0.16 & 0.13 & Silica Sphere $(700 \mathrm{~nm})$ & - & - & - \\
\hline IBN1-YS & 0.16 & 0.13 & IBN1 & 296 & 2.7 & 0.58 \\
\hline MCM41-YS & 0.16 & 0.13 & MCM41 & 200 & 2.7 & 0.80 \\
\hline SBA15NR-YS & 0.16 & 0.13 & SBA15NR & 325 & 2.7 & 0.68 \\
\hline IBN4-YS & 0.16 & 0.13 & IBN4 & 552 & 2.7 & 1.37 \\
\hline
\end{tabular}



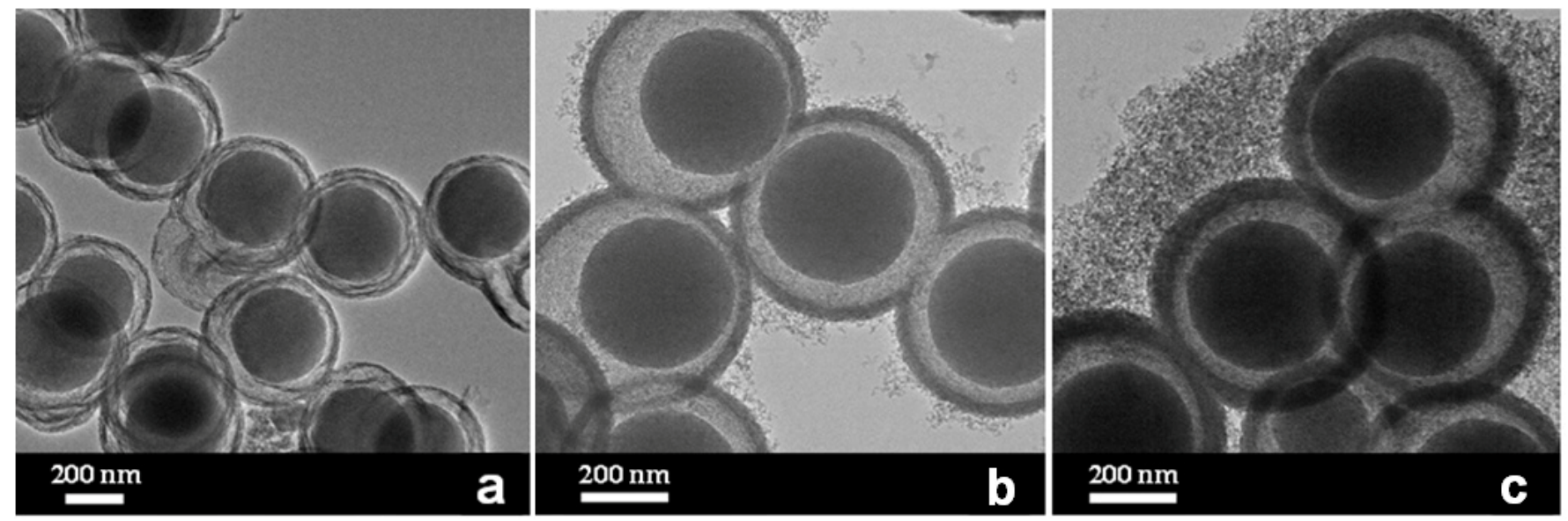

Figure S1 Representative TEM images of the yolk-shell nano-spheres (SS260-YS, synthesized using silica spheres with $260 \mathrm{~nm}$ as core) with different shell thickness synthesized at different TEOS molar amount a) TEOS $=5 \mathrm{mmol}, \mathrm{b}$ ) TEOS $=15 \mathrm{mmol}$, and c) TEOS=20 mmol. 

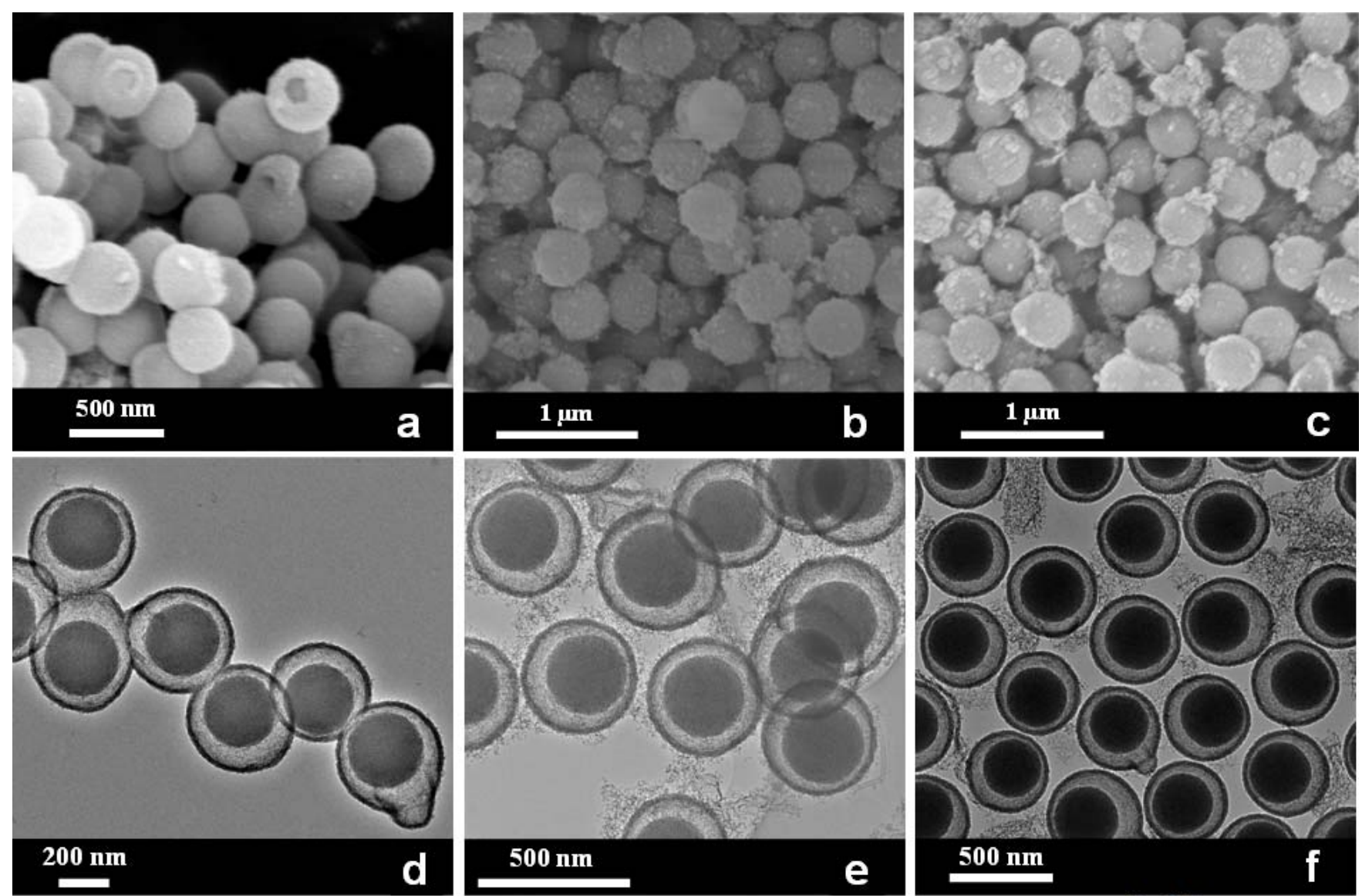

$200 \mathrm{~nm}$

d

0.13

\subsection{6}

\section{Increasing the amount of F127 (g)}

Figure S2. a), b), c) SEM images and d), e), f) TEM images of the yolk-shell nano-spheres synthesized using silica spheres with $260 \mathrm{~nm}$ as cores and different amount of F127. a) and d) $0 \mathrm{~g}$; b) and e) $0.13 \mathrm{~g}$; c) and f) $0.26 \mathrm{~g}$. 


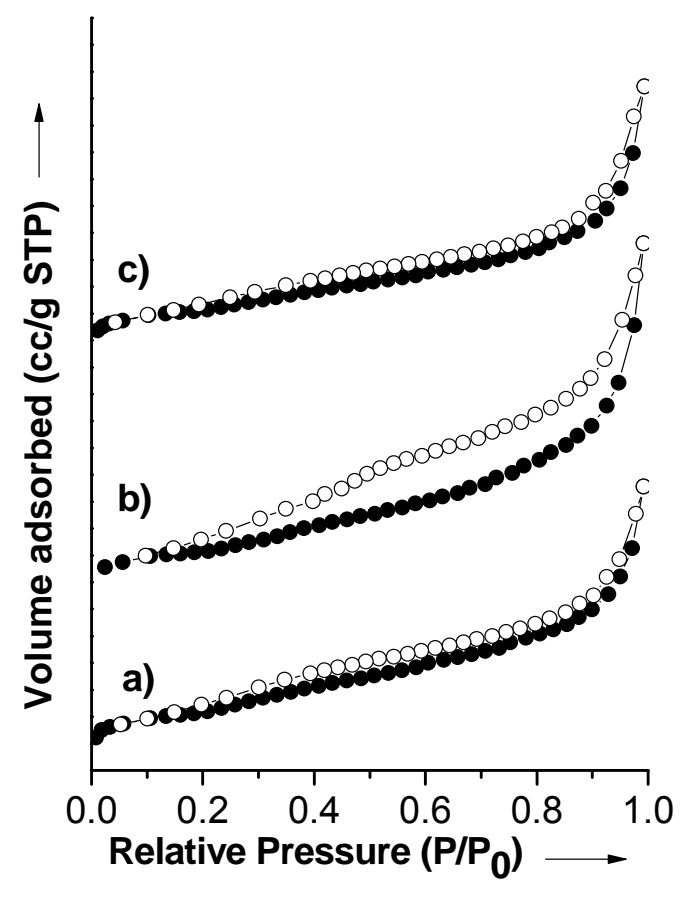

Figure S3. Nitrogen-sorption isotherms of the yolk-shell nano-spheres synthesized using silica spheres with 260 $\mathrm{nm}$ as cores and different amount of F127. a) $0 \mathrm{~g}$; b) $0.13 \mathrm{~g}$; c) $0.26 \mathrm{~g}$. 


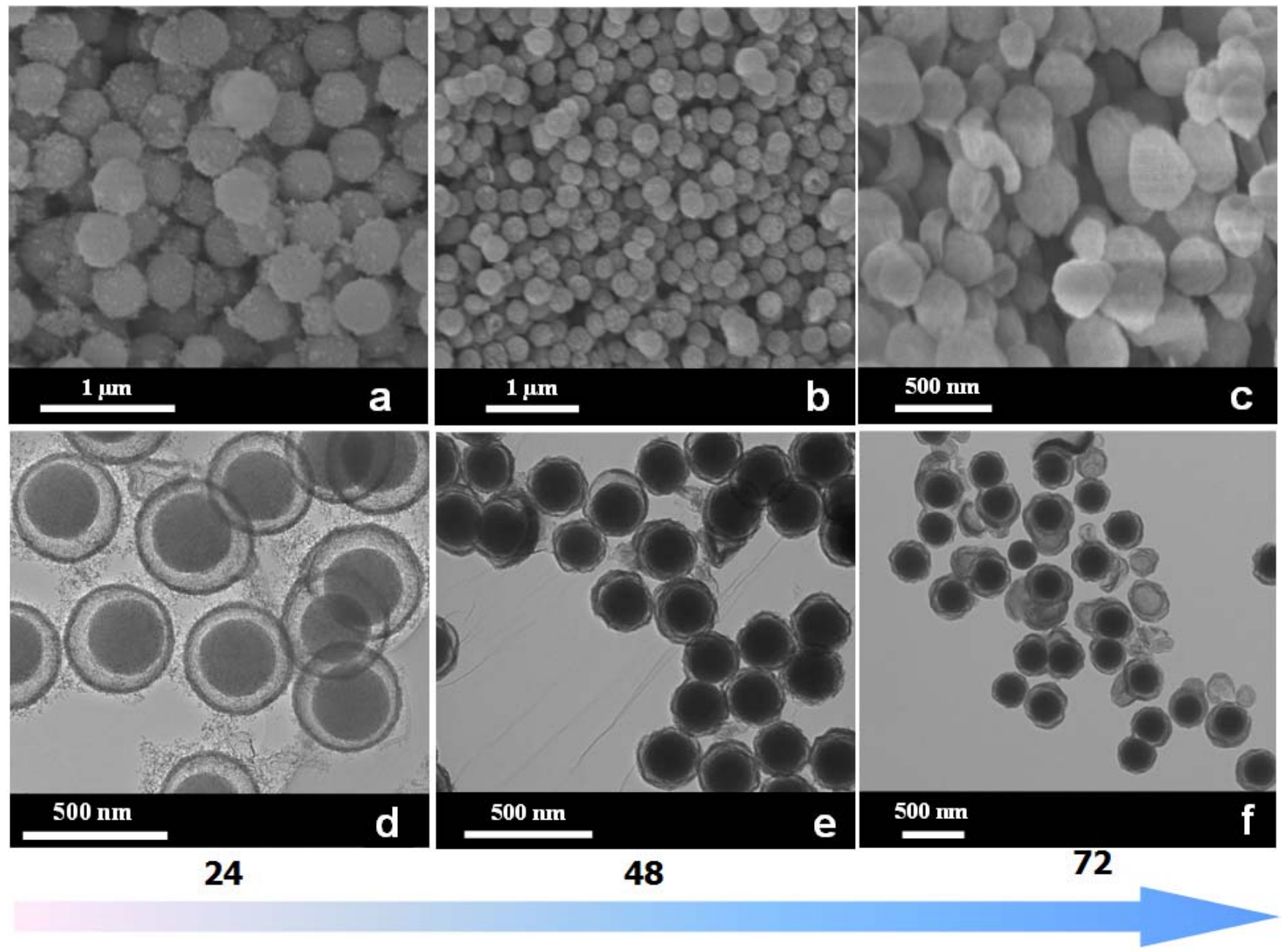

\section{Molar ratio of FC4/F127}

Figure S4. Effect of FC4 amount on the morphological transformation of products with changing the FC4/F127 ratio: a), b), c) SEM images and d), e), f) TEM images. a) and d) FC4/F127=24; b) and e) FC4/F127=48; c) and f) FC4/F127=72. 


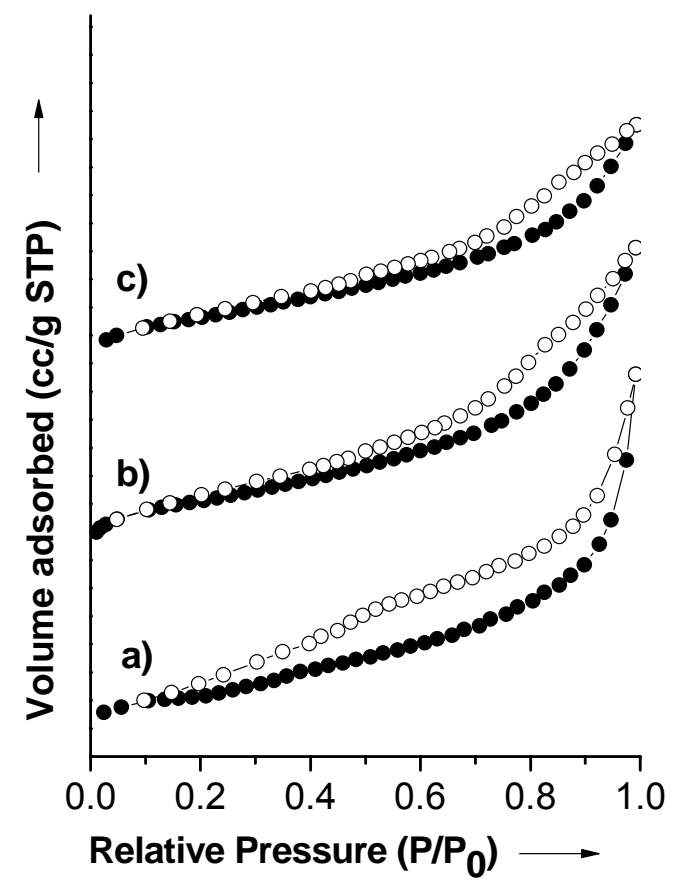

Figure S5. Nitrogen-sorption isotherms of yolk-shell nano-structured products synthesized at FC4/F127 ratio: a), $\mathrm{FC} 4 / \mathrm{F} 127=24 ; \mathrm{b}), \mathrm{FC} 4 / \mathrm{F} 127=48 ; \mathrm{c}), \mathrm{FC} 4 / \mathrm{F} 127=72$. 


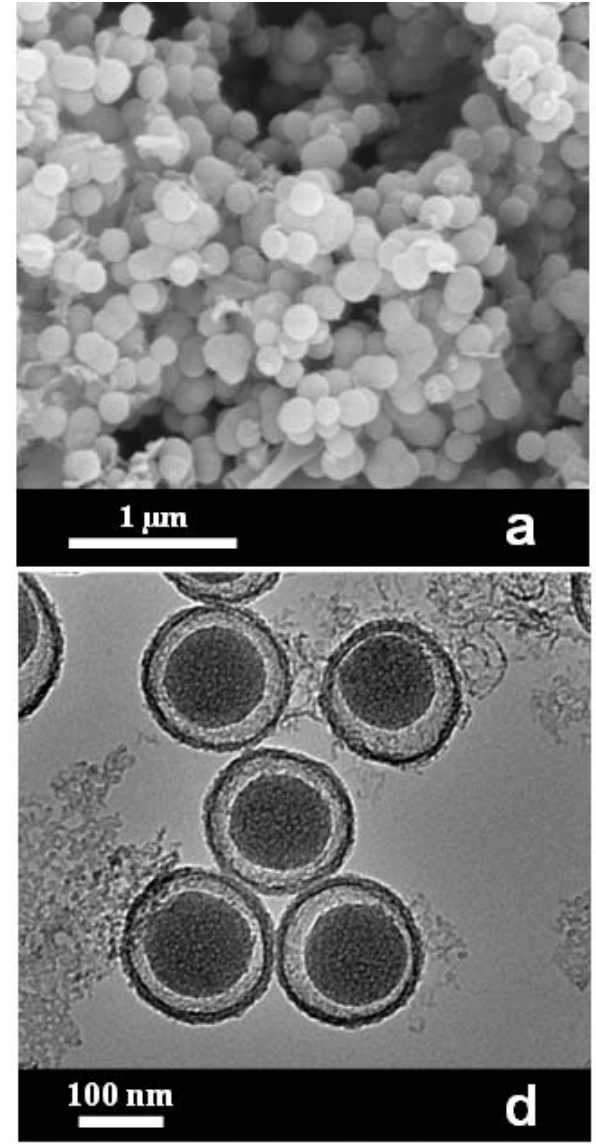

$120 \mathrm{~nm}$
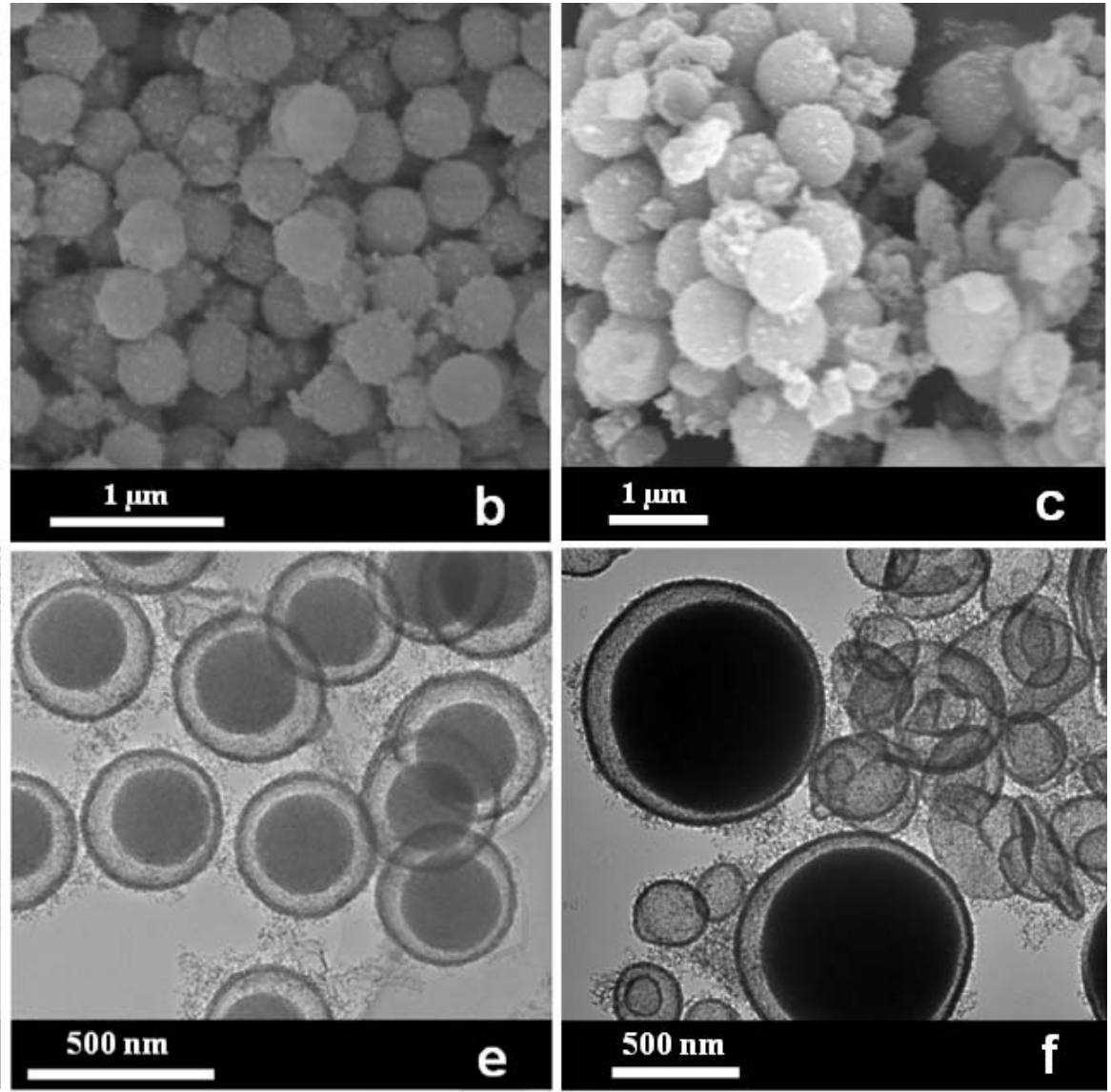

$260 \mathrm{~nm}$

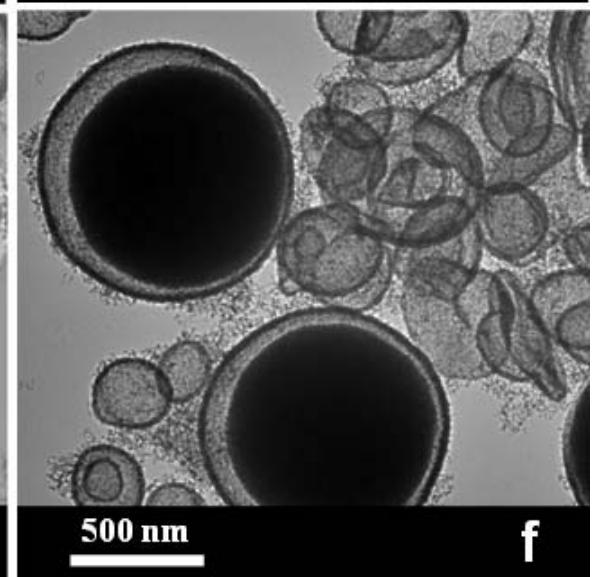

$700 \mathrm{~nm}$

\section{Increasing the core size}

Figure S6. Effect of core size on the morphological transformation of products: a), b), c) SEM images and d), e), f) TEM images. a) and d) core size $=120 \mathrm{~nm}$; b) and e) core size $=260 \mathrm{~nm}$; c) and f) core size=700 $\mathrm{nm}$. 

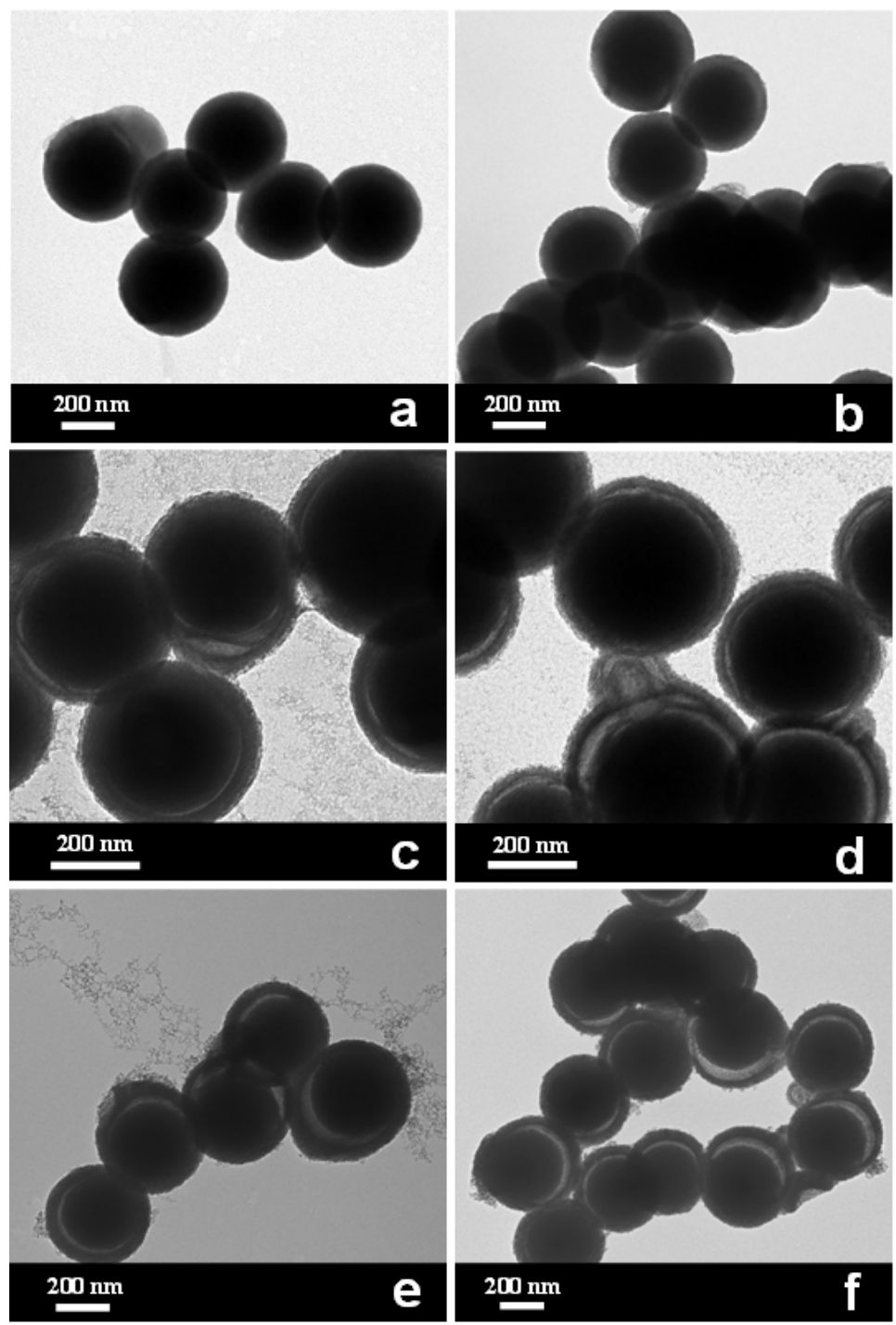

Figure S7 TEM images showing the structural evolution of SS260-YS as a function of time (starting from addition of TEOS into the solution). Panels a), b), c), d), e) and f) correspond to reaction times of $30 \mathrm{~min}, 1 \mathrm{~h}, 2$ h, $4 \mathrm{~h}, 6 \mathrm{~h}$, and f) $20 \mathrm{~h}$, respectively. 


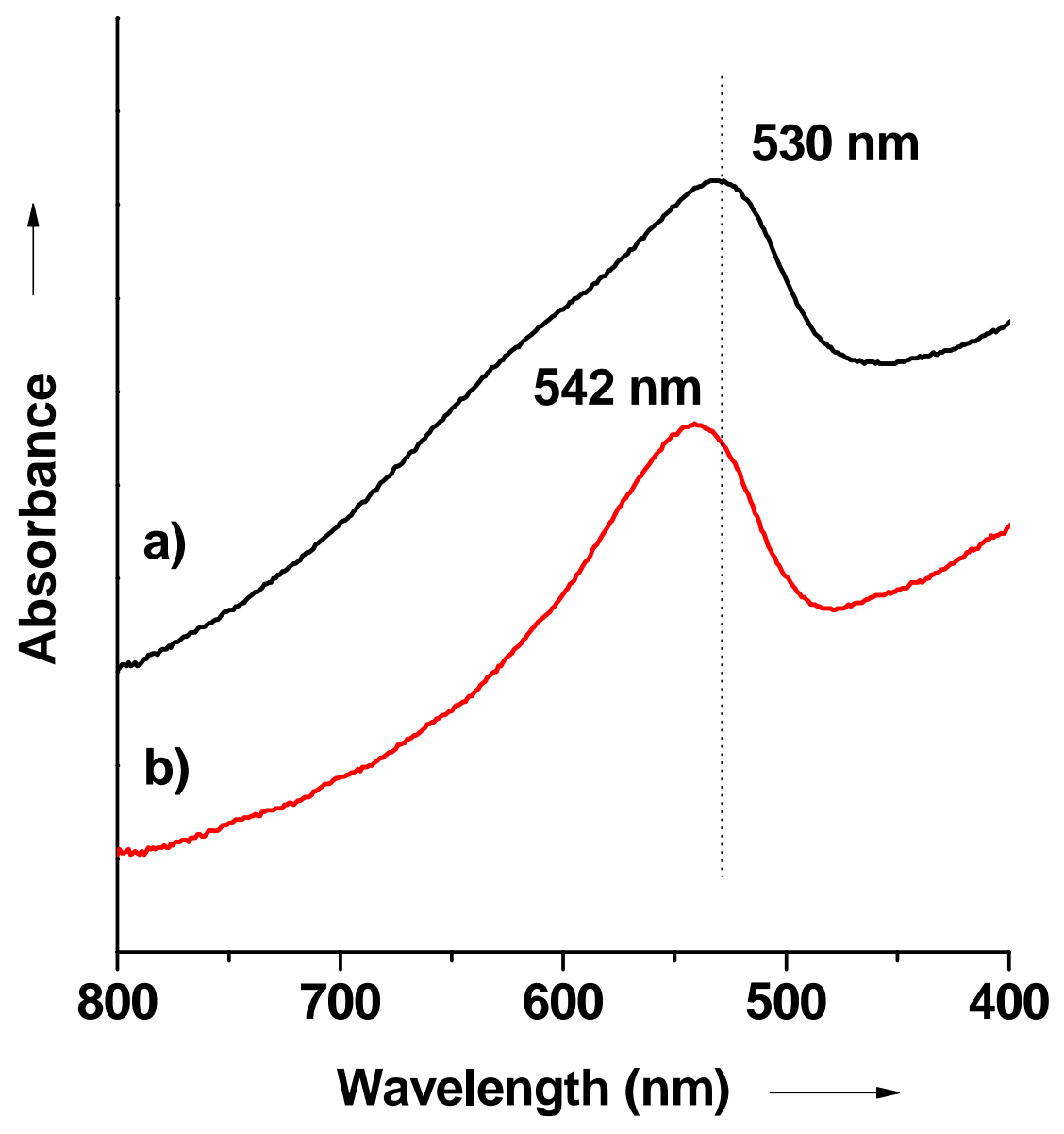

Figure S8. UV-vis spectra of a) Au particles; and b) $\mathrm{Au@SiO} 2$ yolk-shell particles in ethanol solutions. 

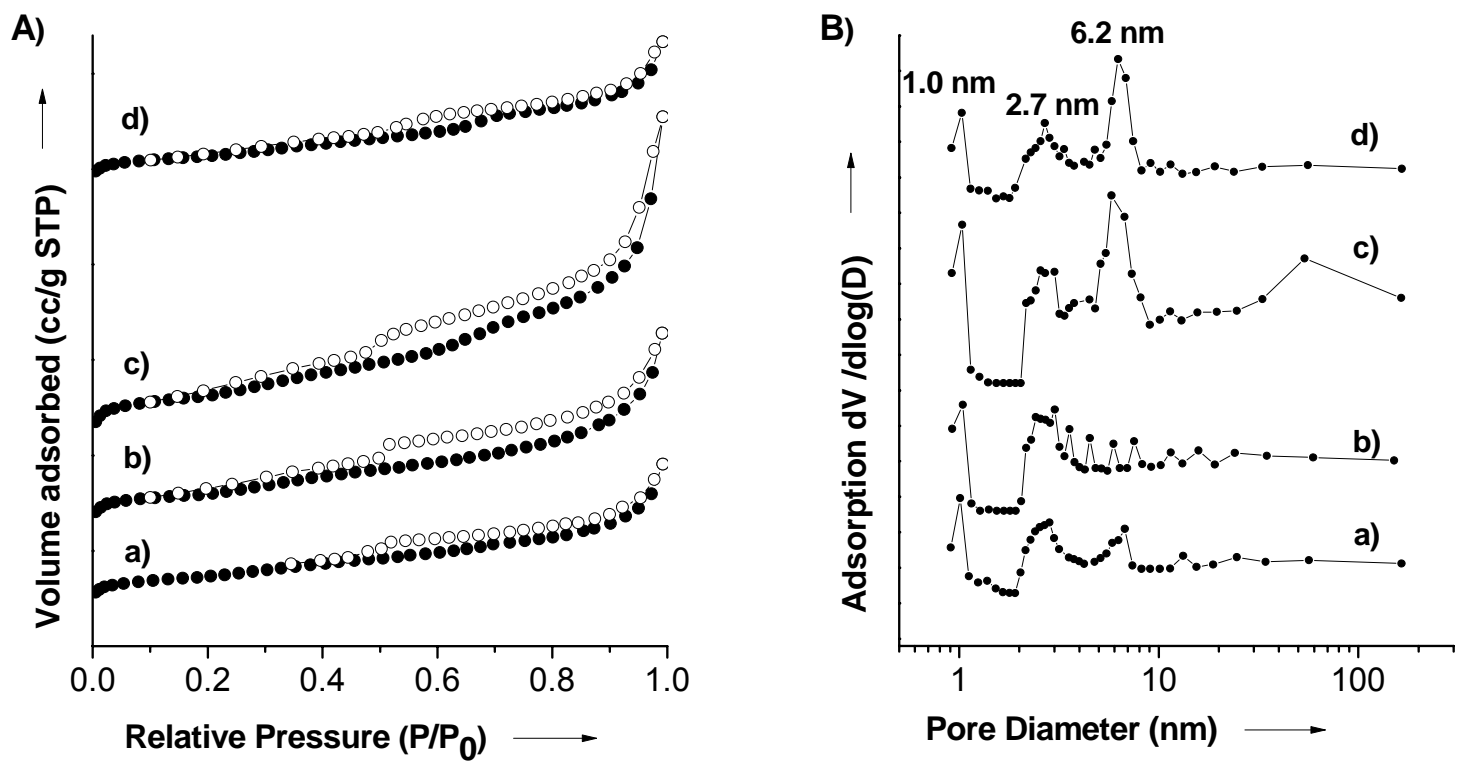

Figure S9. (A) Nitrogen-sorption isotherms and (B) BJH pore-size distributions of various yolk-shell materials: a) IBN1-YS, b) MCM41LP-YS, c) SBA15NR-YS, and d) IBN4-YS. 


\section{S2. Calculation Models and Discussions}

To understand the kinetics for the unique release behavior of ibuprofen from the Yolk-shell structure, we have tried to fit the measured data with the two kinetic models $[7,8]$. The first model is a modified Freundlich model, which has been successfully applied to experimental data of ion exchange or adsorption with clays by many researchers. This model can be described as $\frac{M_{t}}{M_{\infty}}=k t^{n}$, in which $k$ is the release rate coefficient and $n$ is a constant. We have employed this model to fit the experimental data, and the calculated release curves (dashed line) together with the experimental data (solid line) are plotted in Fig. S10 (a) for a comparison (the best fitted $k=0.52$ and $n=0.07$ ). We clearly see from Fig. S10 (a) that this model can reproduce the release curve very well below $t=5 \mathrm{~h}$. At approximately $5 \mathrm{~h}$, the modelling results suddenly deviate from the experimental ones. At $48 \mathrm{~h}$, the modelling results get closer to the experimental data, and then have larger deviations from the experimental data once again. The results indicate there are sudden changes in the drug release behavior at two critical time points at $t_{1}=5 \mathrm{~h}$ and $t_{2}=48 \mathrm{~h}$. To get a better fitting to the experimental release data at longer time stages II and III, we modified the parabolic diffusion model equation. The modified model may be written as follows: $\frac{M_{t}}{M_{\infty}}=k t^{n}+k_{1} t^{n 1}$, where the second term is included to describe the release profiles at stage II ( $5 \mathrm{~h}<t<48 \mathrm{~h}$ ) and stage III ( $t>48 \mathrm{~h})$. The results shown in Figure S10 (b) indicate that the release curve calculated by the new equation (dashed line) is well consistent with the experimental data (solid line) (the best fitted parameters are $k_{1}=0.02$ and $n_{1}=0.03$ for stage II, and $k_{1}=0.02$ and $n_{1}=0.10$ for stage III). Thus two semi-empirical modelling results provide some evidence to support our above expectations about the sudden increases in the release curve at stage II and stage III.

Controlled release can match the physiological requirements of the human body, thus minimizing the total dosage of drugs and preventing the development of biological tolerance and side effects, which arise when the drugs are present at the target sites for excessively long time.

(a)

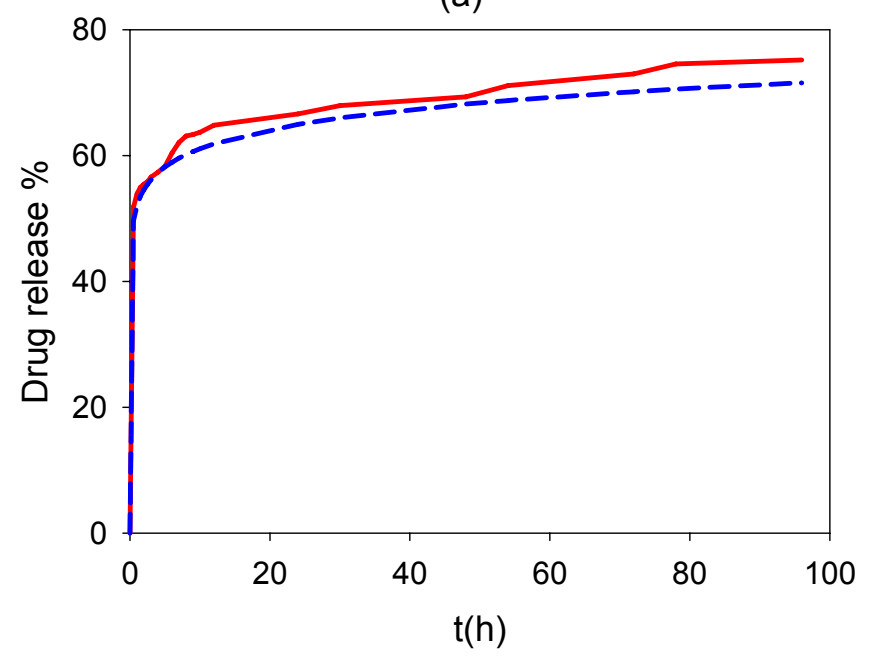

(b)

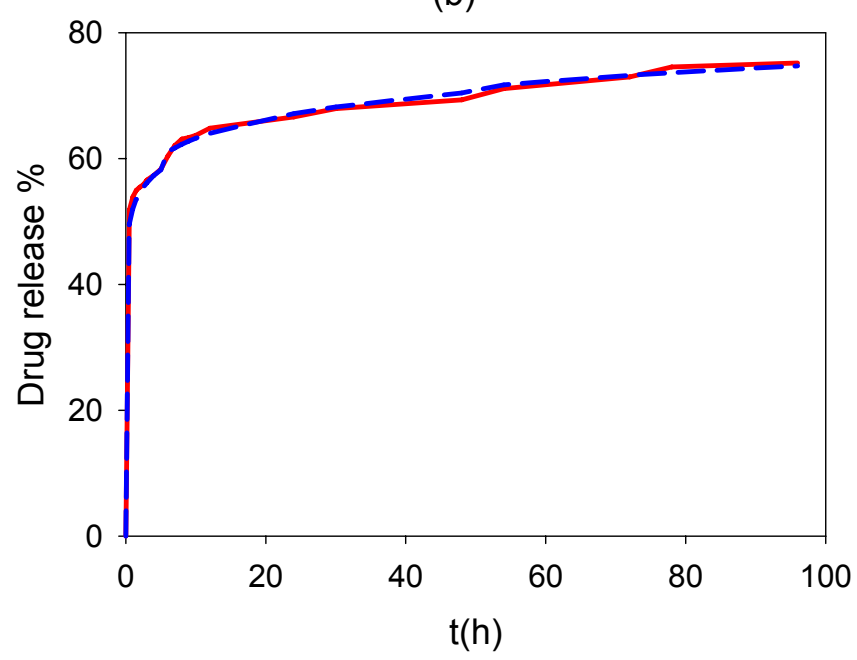

Figure S10. The cumulative release curves of drug ibuprofen from IBN1-YS. Red solid line represents the results from experimental measurements, and blue dashed line represents the results from modelling calculations. 

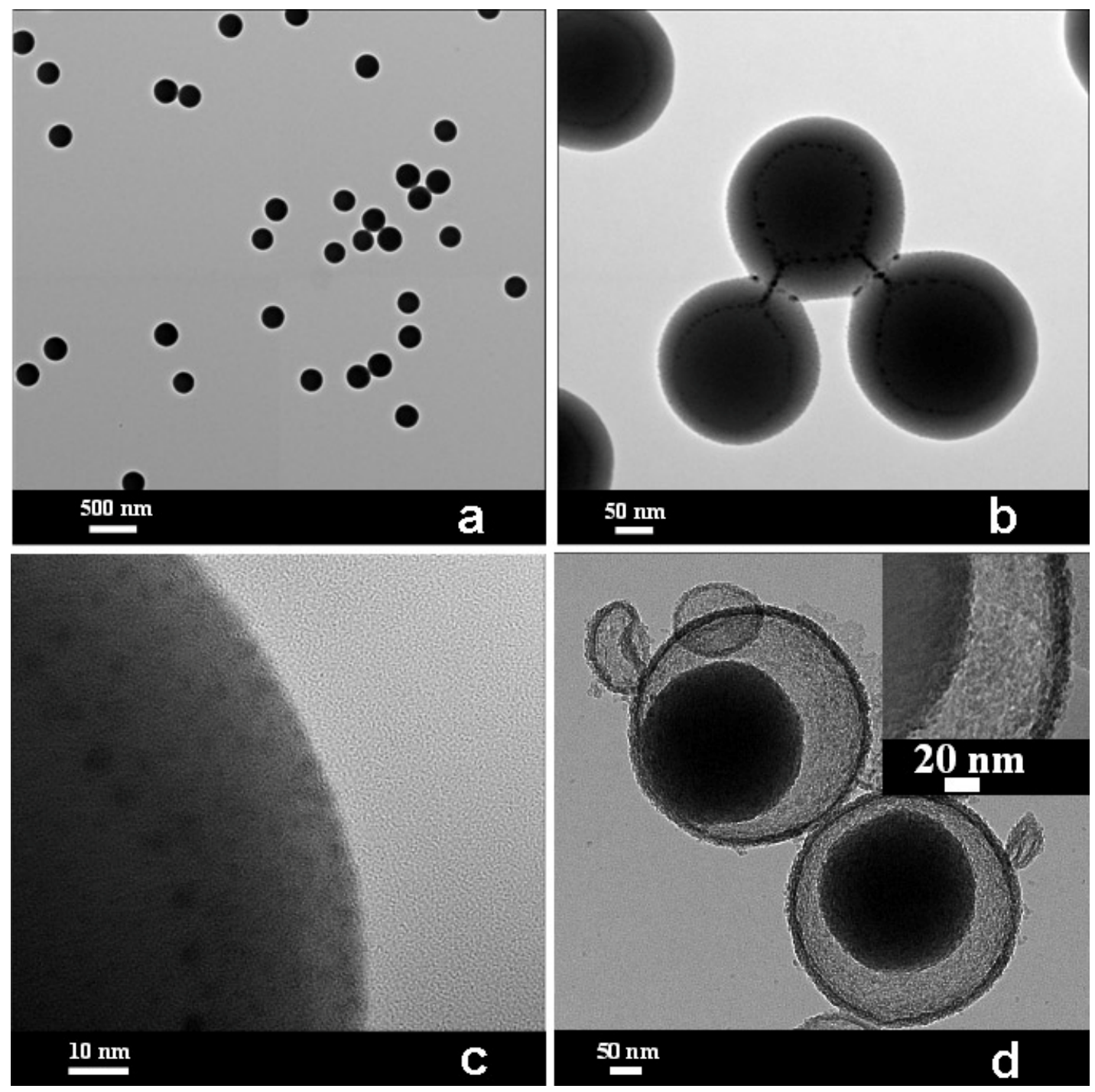

Figure S11. TEM images of a) $\mathrm{SiO}_{2}-\mathrm{Au}$, in which 2-nm Au nano-particles are assembled on $260 \mathrm{~nm}$ silica spheres; b) $\mathrm{SiO}_{2}$-Au-YS yolk-shell structures, in which 2-nm Au nano-particles coated on $260 \mathrm{~nm}$ silica spheres are encapsulated into the hollow silica shells.

\section{Reference}

[1] W. Stober, A. Fink, E. Bhon, J. Colloid Interface Sci. 1968, 26, 62.

[2] Q. Cai, Z. S. Luo, W. Q. Pang, Y. W. Fan, X. H. Chen, F. Z. Cui, Chem. Mater. 2001, $13,258$.

[3] Y. Han, J. Y. Ying, Angew. Chem. Int. Ed. 2005, 44, 288.

[4] X. L. Ji, K. T. Lee, M. Monjauze, L. F. Nazar, Chem. Commun. 2008, 4288.

[5] H. Xu, N. H. Tong, L. L. Cui, Y. Lu and H. C. Gu, J. Magnetism Magnetic Mater. 2007, $311,125$.

[6] a) D. G. Duff, A. Baiker, Langmuir 1993, 9, 2301; b) J. Kim, J. E. Lee, J. Lee, Y. Jang, S. W. Kim, K. An, J. H. Yu, T. Hyeon, Angew. Chem. Int. Ed. 2006, 45, 4789.

[7] Z. Li, Langmuir 1999, 15, 6438.

[8] J. Yang, Y. Han, M. Park, T. Park, S. Hwang, and J. Choy, Chem. Mater. 2007, 19, 2679. 